\title{
Aza-Cope Rearrangement-Mannich Cyclizations for the Formation of Complex Tricyclic Amines: Stereocontrolled Total Synthesis of $( \pm)$-Gelsemine
}

\author{
William G. Earley ${ }^{1 \mathrm{a}}$, Jon E. Jacobsen ${ }^{1 b}$, Andrew Madin ${ }^{1 \mathrm{c}}$, G. Patrick Meier ${ }^{1 \mathrm{~d}}$, Christopher \\ J. O'Donnell ${ }^{1 \mathrm{e}}$, Taeboem Oh $^{1 \mathrm{f}}$, David W. Old ${ }^{1 \mathrm{~g}}$, Larry E. Overman ${ }^{\star}$, and Matthew J. Sharp ${ }^{1 \mathrm{~h}}$

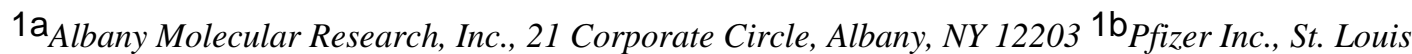 \\ Laboratories, 700 Chesterfield Parkway West, Chesterfield, MO $63017^{1 \mathrm{C}}$ Merck Sharp \& Dohme \\ Laboratories, Terlings Park, Harlow, Essex CM20 2QR, England $1 \mathrm{~d}_{\text {Medical University of South Carolina, }}$ \\ Department of Medicinal Chemistry, 171 Ashley Ave., Charleston, SC $294251 \mathrm{e}_{\text {Pfizer Inc., Groton/New }}$ \\ London Laboratories, Eastern Point Road, 8220-4044, Groton, CT $06340{ }^{1 \mathrm{f}}$ California State University

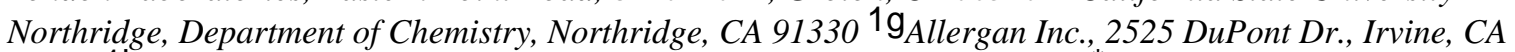

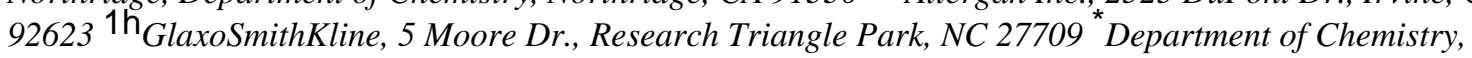 \\ University of California, Irvine, 516 Rowland Hall, Irvine, California 92697-2025
}

\begin{abstract}
A detailed examination of the use of aza-Cope rearrangement-Mannich cyclization sequences for assembling the azatricyclo[4.4.0.0 $\left.0^{2,8}\right]$ decane core of gelsemine is described. Iminium ions and $\mathrm{N}$ acyloxyiminium ions derived from endo-oriented 1-methoxy- or 1-hydroxybicyclo[2.2.2] oct-5enylamines do not undergo the first step of this sequence, cationic aza-Cope rearrangement to form cis-hydroisoquinolinium ions. However, the analogous base-promoted oxy-aza-Cope rearrangement does take place to form cis-hydroisoquinolones containing functionality that allows iminium ions or $\mathrm{N}$-acyloxyiminium ions to be generated regioselectively in a subsequent step. Mannich cyclization of $c i s$-hydroisoquinolones prepared in this way efficiently assembles the azatricyclo[4.4.0.0 $\left.0^{2,8}\right]$ decane unit of gelsemine. Using a sequential base-promoted oxy-aza-Cope rearrangement/Mannich cyclization sequence, gram quantities of azatricyclo[4.4.0.0 $\left.0^{2,8}\right]$ decanone 18, a central intermediate in our total of $( \pm)$-gelsemine, was prepared from 3-methylanisole in 12 steps and $16 \%$ overall yield.
\end{abstract}

\section{Background}

The genus Gelsemium (Loganiaceae) is comprised of three species, of which $G$. sempervirens (Carolina or yellow jasmine) has been the most extensively investigated for the presence of alkaloids. ${ }^{2}$ This particular plant is indigenous to the southeastern United States and has a long history of medicinal applications. Wormley first detected the presence of alkaloids in extracts of G. sempervirens in $1870 .{ }^{3}$ In 1876, Sonnenschein isolated the principal component of the species, gelsemine (1), as an amorphous base (Figure 1). ${ }^{4}$ The correct molecular formula of gelsemine, $\mathrm{C}_{20} \mathrm{H}_{22} \mathrm{~N}_{2} \mathrm{O}_{2}$, was established in 1910 by Moore. ${ }^{5}$ More than 70 years of degradative studies failed to elucidate the structure of gelsemine, but demonstrated that gelsemine had the same five functional groups that are present in strychnine. ${ }^{2}$ Finally, in 1959, the structure was solved independently by two laboratories: Lovell and co-workers used 
X-ray crystallography to determine the structure of the hydrochloride and hydroiodide salts of gelsemine, ${ }^{6}$ whereas Conroy and Chakrabarti derived the same structure from a combination of biosynthetic rationale (attributed to Woodward) and an early application of ${ }^{1} \mathrm{H}$ NMR spectroscopy for structure elucidation. ${ }^{7,8}$ Gelsemine's presumed biosynthesis from secologanin suggests the absolute configuration depicted in Figure 1, a supposition verified in 2000 by Fukuyama's enantioselective total synthesis. ${ }^{9}$

Since these early reports, many structurally related Gelsemium alkaloids have been reported (Figure 1). ${ }^{10-15}$ Among these, gelsemicine (5) is the most toxic and appears to be largely responsible for the CNS stimulant activity that is characteristic of the Gelsemium extracts. ${ }^{12}$ Koumine (10), which has enjoyed a long history of use in traditional Chinese medicine, is the most abundant alkaloid found in G. elegans. ${ }^{16}$ Gelsemine (1), gelsevirine (2), gelsedine (6), gelsenicine (9), gelsemine $N$-oxide, 19-(S)-hydroxydihydrogelsevirine and 19-(R)hydroxydihydrogelsevirine (11) are among the numerous alkaloids isolated from G. elegans. 17 The least studied species is G. rankinii, from which rankinidine (14), 21-oxogelsevirine $(\mathbf{4}), 19-(R)$-acetoxydihydrogelsevirine (12) and 19- $(R)$-hydroxydihydrogelsemine (13) have been isolated. ${ }^{17 \mathrm{a}, 18}$

The six diverse rings of gelsemine (1) are assembled into a compact cage. The unusual and densely functionalized nature of this hexacyclic structure provoked intense efforts to synthesize gelsemine ${ }^{19}$ These studies stimulated the development of many innovative synthetic methods, 20,21 culminating in total syntheses of ( \pm -gelsemine by the groups of Johnson, ${ }^{22}$ Speckamp, ${ }^{23}$ Hart, ${ }^{24}$ Fukuyama, ${ }^{25}$ Overman, ${ }^{26}$ and Danishefsky, ${ }^{27}$ and of (+)-gelsemine by Fukuyama and co-workers. ${ }^{9}$

\section{Initial Synthesis Planning}

The retrosynthetic analysis that propelled our efforts to synthesize gelsemine is outlined in Figure 2. We envisaged forming the hydropyran ring last, for example by intramolecular etherification of an intermediate such as 15. It was hoped that the spirooxindole unit of pentacyclic intermediate $\mathbf{1 5}$ could be formed by cyclization of an appropriately functionalized $\alpha, \beta$-unsaturated amide such as $\mathbf{1 6}$. At the outset, we entertained the possibility that either radical-chain or metal-catalyzed processes might accomplish this conversion. At the time our efforts began, precedent that a sterically congested quaternary carbon center such as $\mathrm{C} 7$ could be fashioned by either process was lacking. Nonetheless, we adopted this strategy in part because it would present opportunities for developing new methods to address what still remains a challenging problem in organic synthesis: stereocontrolled construction of quaternary carbon stereocenters. ${ }^{28}$ As it happened, the discovery that intramolecular Heck reactions could solve this general problem with remarkable facility is the most significant outcome of our endeavors in this area. 29

We anticipated that cyclization precursor $\mathbf{1 6}$ could be prepared from the azatricyclo [4.4.0.0 $0^{2,8}$ ]decanone 17. This latter intermediate encodes a 3-acylpyrrolidine unit, suggesting that it might be available by aza-Cope-Mannich reaction of bicyclo[2.2.2] octyliminium ion 19. ${ }^{30,31}$ The projected aza-Cope-Mannich transformation is outlined in more detail in Scheme 1. Although thermal Cope rearrangements of bicyclo[2.2.2]octenes bearing endo alkenyl substituents have high activation barriers, ${ }^{32}$ these rearrangements and the corresponding oxyCope rearrangements have been employed to prepare functionalized cis-decalins. ${ }^{33}$ Because of the kinetic activation provided by the positively charged nitrogen atom, $31 \mathrm{~b}$ we expected the conversion of iminium cation 19 to cis-hydroisoquinolinium cation 21 to occur at significantly lower temperatures than those required for similar sigmatropic reorganizations of hydrocarbons. At the outset, Mannich cyclization of iminium ion 21 to yield azatricyclo [4.4.0.0 $0^{2,8}$ ]decanone $\mathbf{1 7}$ was viewed as the potentially problematic step of this sequence for 
two reasons: (1) the ring strain of the azatricyclo[4.4.0.0 $\left.0^{2,8}\right]$ decane ring system, ${ }^{34}$ and (2) the requirement that the tetrahydropyridinium ring adopt a boat conformation (as depicted in conformer 22) to achieve acceptable orbital overlap for the intramolecular Mannich reaction. $31 \mathrm{a}, 35$

The intramolecular Mannich reaction depicted in Scheme 1 was without precedent; however, the literature provided examples of other cyclizations that form tricyclo[4.4.0.0 $\left.0^{2,8}\right]$ decane ring systems. ${ }^{36}$ For example, closure of an analogous bond is involved in a tosylate displacement reaction leading to sativene. ${ }^{37}$ A more relevant example of this bond construction is found in Woodward's base-promoted conversion of $\alpha$-santonin (23) to santonic acid, which is particularly germane as the intramolecular Michael reaction involved in this sequence, like the Mannich reaction, presumably is reversible (Scheme 2). ${ }^{38}$

With these considerations in mind, we set out to explore the feasibility of the aza-CopeMannich reaction to prepare the azatricyclo[4.4.0.0 $\left.0^{2,8}\right]$ decane ring system of gelsemine (1). At the time our studies began, this cascade reaction had just been invented 30 and never had been examined in the bicyclo[2.2.2] octyl series, nor with a substrate as complex as 19. Although the direct way to access azatricyclodecanone intermediate $\mathbf{1 7}$ depicted in Scheme 1 ultimately proved unworkable, a base-promoted variant of aza-Cope-Mannich chemistry eventually provided access to related intermediate $\mathbf{1 8}$ (Figure 2). Full details of our investigations into iminium-ion transformations in the bicyclo[2.2.2]octyl series and the development of a basepromoted 2-aza-Cope rearrangement are the subject of this account. ${ }^{39}$ The development of Heck cyclization chemistry to prepare spirooxindoles, and the endgame strategy that ultimately led to $\left( \pm\right.$ )-gelsemine $(\mathbf{1})$, are presented in the accompanying paper. ${ }^{40}$

\section{Results and Discussion}

\section{Attempted Construction of Azatricyclo[4.4.0.0 2,8 decane Intermediates by Cationic Aza- Cope-Mannich Cyclizations}

Bicyclooctenylamine 29 was chosen for our inaugural investigations of the projected azaCope-Mannich transformation (Scheme 3). The synthesis of this amine commenced with the reaction of cyclohexadiene 24, the Birch-reduction product of 3-methylanisole, with methyl acrylate in the presence of a catalytic amount of dichloromaleic anhydride to provide a separable $2.7: 1$ mixture of endo, $\mathbf{2 5}$, and exo, 26, adducts. ${ }^{41}$ The methyl ester of the endo product $\mathbf{2 5}$ was saponified and the resulting acid was converted to carbamate 28 by a standard Curtius-rearrangement sequence. ${ }^{42}$ Reduction of this product with alane ${ }^{43}$ provided bicyclooctenylamine $\mathbf{2 9}$ in $45 \%$ overall yield from Diels-Alder product $\mathbf{2 5}$.

With amine 29 in hand, we turned to examine the proposed cationic aza-Cope-Mannich transformation. Reaction of bicyclooctenylamine 29 with paraformaldehyde and camphorsulfonic acid (CSA) in refluxing benzene for extended periods of time resulted only in the recovery of starting material. The use of higher boiling solvents such as toluene or chlorobenzene was also unsuccessful, as paraformaldehyde sublimed from these reaction mixtures. However, heating bicyclooctenylamine $\mathbf{2 9}$ with 1.1 equiv of paraformaldehyde, 0.98 equiv of camphorsulfonic acid and a slight excess of sodium sulfate in acetonitrile at $100{ }^{\circ} \mathrm{C}$ provided one major product, which was isolated in $76 \%$ yield. The presence of exomethylene and methoxy groups, readily apparent in ${ }^{1} \mathrm{H}$ and ${ }^{13} \mathrm{C}$ NMR spectra, established that this product was not the desired azatricyclo[4.4.0.0 $\left.0^{2,8}\right]$ decanone, but rather the 10-methylene-4-azatricyclo $\left[4.3 .1 .0^{3,7}\right]$ decane 32. Iminium-ion intermediate $\mathbf{3 0}$ had not undergone aza-Cope rearrangement, but rather aza-Prins cyclization at the proximal terminus of the alkene double bond to generate tertiary carbenium ion $\mathbf{3 1}$ and, ultimately, azatricyclodecane $\mathbf{3 2}$. 
We hypothesized that the electron-releasing methyl group at C5 of iminium-ion intermediate 30 was responsible for the undesired cyclization to generate 32. As a substituent at C5 must ultimately evolve to the angular vinyl group of gelsemine, considerable variation in the electronic properties of this group would be permitted. Therefore, we turned to explore the chemistry of related bicyclo[2.2.2] octenyl formaldiminium ions having less electron-rich carbon-carbon double bonds.

The outcome of generating a formaldiminium ion from a bicyclo[2.2.2]octenylamine having an unsubstituted double bond was explored first. The straightforward preparation of such a precursor, bicyclo[2.2.2] octenylamine $\mathbf{3 5}$, from acid $\mathbf{3 3}^{44}$ is summarized in Scheme 4. Exposing bicyclooctenylamine $\mathbf{3 5}$ to paraformaldehyde and camphorsulfonic acid in acetonitrile or methanol at $100{ }^{\circ} \mathrm{C}$ resulted in no reaction. Heating these reactants to $200{ }^{\circ} \mathrm{C}$ in toluene in a sealed tube also returned the starting secondary amine 35 , together with its $N, N$ dimethylamine congener. As we had recorded considerable success in initiating other azaCope-Mannich transformations of formaldiminium ions from cyanomethylamine precursors, 31,45 octenylamine 35 was allowed to react with formalin and potassium cyanide to give cyanomethylamine 36. Heating this precursor with camphorsulfonic acid and paraformaldehyde also failed to affect the desired aza-Cope-Mannich reaction. The formation of the $\mathrm{N}$-methylated product confirmed that a formaldiminium ion was being generated; however, aza-Cope rearrangement or Mannich cyclization of this intermediate was slower than its reduction. 46

As $N$-acyloxyiminium ions are more reactive than iminium ions and are readily generated by the acid-promoted reaction of formaldehyde with secondary carbamates, ${ }^{47,48}$ we also examined the direct reaction of bicyclooctenyl carbamate $\mathbf{3 4}$ with paraformaldehyde. When this condensation was carried out in formic acid at $50{ }^{\circ} \mathrm{C}$ using 1.3 equiv of paraformaldehyde, azatricyclo[4.3.1. $\left.0^{3,7}\right]$ decyl formate 37 , the product of aza-Prins cyclization, was produced in high yield.

We turned next to explore whether introduction of an electron-withdrawing group at $\mathrm{C} 5$ of the bicyclooctenylamine precursor might prevent iminium ion-alkene (aza-Prins) cyclization, thus allowing the desired sigmatropic reorganization to be realized. The synthesis of such a precursor, ester 40, began with selenium dioxide oxidation of bicyclo[2.2.2] octenyl carbamate $\mathbf{2 8}$ in refluxing dioxane to form aldehyde $\mathbf{3 8}$ in $89 \%$ yield (Scheme 5). Sodium chlorite oxidation of this intermediate provided acid 39 in $83 \%$ yield, which, upon reaction with methyl iodide and potassium carbonate, delivered methyl ester $\mathbf{4 0}$ in $89 \%$ yield.

A new reaction manifold was revealed when carbamate ester $\mathbf{4 0}$ was allowed to react at room temperature with paraformaldehyde in trifluoroacetic acid (TFA), a reaction that produced one major tricyclic product, trifluoroacetate 42. Single-crystal X-ray analysis established that this crystalline product had a rearranged carbon skeleton. Tricyclic diester $\mathbf{4 2}$ likely arises by initial aza-Prins cyclization to generate carbocation intermediate 41, which undergoes WagnerMeerwein rearrangement and trapping of the resulting carbocation with trifluoroacetic acid.

\section{Construction of Azatricyclo[4.4.0.0 2,8$]$ decanes by Sequential Base-Promoted Aza-Cope Rearrangement and Iminium Ion Cyclization}

General Considerations-The failure to realize the desired aza-Cope reorganization in the bicyclo[2.2.2] octenyl series, even with intermediates having an electron-withdrawing group at $\mathrm{C} 5$ of the bicyclooctenylamine precursor, forced us to consider other options. ${ }^{49}$ As a result of the high electrophilicity of the iminium ion and $N$-acyloxyiminium ion functional groups, bond formation is likely advanced with respect to bond cleavage in iminium ion and $\mathrm{N}$ acyloxyiminium ion [3,3]-sigmatropic rearrangements. In the mechanistic limit, these rearrangements could occur by a stepwise cyclization-Grob fragmentation sequence. Thus, the 
energy of the transition state of the cationic aza-Cope rearrangement of $\mathbf{4 3} \rightarrow \mathbf{4 5}$ is expected to be influenced strongly by the stability of the tricyclic ring system defined by the sigmatropic rearrangement transition structure $\mathbf{4 4}$ (Figure 3). A simplified model for this transition structure would be tricyclo[4.4.0.0 $0^{0,0}$ decane (47, twistane). Molecular mechanics calculations predict that this hydrocarbon is $2.2 \mathrm{kcal} / \mathrm{mol}$ higher in energy than tricyclo[4.3.1.0 $\left.0^{3,7}\right]$ decane $(\mathbf{4 6}) .^{34}$ Thus, the greater strain of the twistane tricyclodecane skeleton provides a rationale why the iminium- and $N$-acyloxyiminium-ion intermediates generated in the reactions summarized in Scheme 3-Scheme 5 cyclize to generate 4-azatricyclo[4.3.1. $\left.0^{3,7}\right]$ decyl carbenium ion intermediates rather than undergo aza-Cope rearrangements.

We hypothesized that a potential way to relieve the constraints imposed by the rigid bicyclo [2.2.2] octenyl ring system would be to alter the electronic nature of the rearranging system in such a way to advance bond cleavage relative to bond formation in the sigmatropic reorganization. The seminal contributions of Evans and Goddard 50 to the origin of base acceleration $^{51}$ in the oxy-Cope rearrangement suggested that an analogous base-promoted oxy-aza-Cope rearrangement would have a less constrained transition structure than that of the cationic rearrangement depicted in Figure 3.

Ultimately Successful Synthesis of Azatricyclo[4.4.0.0 2,8]decane 18-Although rarely used, base-promoted aza-Cope-Mannich reactions are known. ${ }^{52}$ To explore this transformation in the azabicyclo[2.2.2] octene ring system, we needed to assemble bicyclo [2.2.2] oct-5-ene-2-amines in which the bridgehead C1 substituent is hydroxyl in order for the powerful activating effect of an alkoxide substituent ${ }^{51}$ to be brought into play. Initially we examined demethylation of Diels-Alder products 28 and $\mathbf{2 9}$ (see Scheme 3) to gain access to such substrates. However, all attempts to remove the methyl group from these precursors with trimethylsilyl iodide, boron tribromide or boron trifluoride/ethanethiol failed to give the corresponding alcohols.

However, we were able to prepare hydroxyl bicyclooctenylamine $\mathbf{5 3}$ quite smoothly by a DielsAlder strategy using a triisopropylsilyl (TIPS) group to protect what will become the C1 hydroxyl substituent of the bicyclo[2.2.2] octenylamine (Scheme 6). This sequence began with kinetic deprotonation of $\beta, \gamma$-unsaturated ketone $\mathbf{4 8}^{53}$ with lithium diisopropylamide at $-78^{\circ}$ $\mathrm{C}$, followed by quenching with triisopropylsilyl trifluoromethanesulfonate to give siloxy diene 49 in $92 \%$ overall yield from 3-methylanisole, the precursor of enone 48. Diels-Alder cycloaddition of diene 49 with methyl acrylate at $-78^{\circ} \mathrm{C}$ in the presence of $\mathrm{AlCl}_{3}$ provided an 8:1 mixture of endo/exo cycloadducts in nearly quantitative yield. The major epimer $\mathbf{5 0}$ was separated by chromatography and saponified to yield acid $\mathbf{5 1}$. Curtius rearrangement of $\mathbf{5 1}$, with trapping of the resulting isocyanate by ethanol, provided bicyclooctenyl carbamate $\mathbf{5 2}$ in $68 \%$ yield. ${ }^{54}$ Removal of the alcohol protecting group from this intermediate with tetrabutylammonium fluoride, followed by cleavage of the carbamate with potassium hydroxide delivered the hydroxyl bicyclooctenylamine $\mathbf{5 3}$ in $64 \%$ yield for the two steps.

With hydroxyl bicyclo[2.2.2]octenylamine $\mathbf{5 3}$ in hand, we turned to investigate the projected base-promoted aza-Cope-Mannich sequence (Scheme 7). A method for generating the labile formaldehyde imine derivative of $\mathbf{5 3}^{55}$ under strongly basic conditions that would also deprotonate the bridgehead alcohol was required. Such a method was available, as we had shown earlier that formaldehyde imines could be generated in situ by base-promoted fragmentation of secondary cyanomethylamines. ${ }^{56}$ Cyanomethylamine 54 was prepared conveniently in $84 \%$ yield by reaction of the hydrochloride salt of primary amine $\mathbf{5 3}$ with formalin and $\mathrm{KCN}$ in aqueous THF. Exposure of this product to an excess of $\mathrm{KH}$ at room temperature in THF affected the desired base-promoted oxy-aza-Cope rearrangement to generate cis-hydroisoquinoline alkoxide 56. Upon aqueous workup, the corresponding ketone 57, albeit impure, was isolated in low yield. We soon discovered that quenching the basic 
reaction at low temperature with an aqueous $\mathrm{HCN} / \mathrm{KCN}$ buffer solution allowed the cis-3cyanohydroisoquinolone $\mathbf{5 8}$ to be isolated in $67 \%$ yield. 57

We had succeeded in promoting the desired sigmatropic rearrangement; however, alkoxide imine 56 did not cyclize to generate an azatricyclo[4.4.0.0 $\left.0^{2,8}\right]$ decane product. This outcome, which contrasts with the formation of 3-acylpyrrolidine and hydroindolone conjugate bases from related base-promoted aza-Cope-Mannich transformations, ${ }^{52}$ likely reflects the strain of the azatricyclo[4.4.0.0 $\left.0^{2,8}\right]$ decane ring system. The increase in basicity that would result when a potassium enolate is transformed to a potassium amide renders the cyclization of imine enolate 56 much less favorable than the related junction of iminium ion and enol functional groups (classical Mannich cyclization).

Decoupling the base-promoted sigmatropic reorganization and the Mannich cyclization step finally allowed the long-sought azatricyclo[4.4.0.0 $\left.0^{2,8}\right]$ decanones to be constructed. To eventually facilitate the Mannich cyclization, cis-3-cyanohydroisoquinolone 58 was converted to its tertiary amine congener $\mathbf{5 9}$ by reaction with methyl methanesulfonate and diisopropylethylamine in refluxing chloroform (Scheme 7). To our delight, exposure of this intermediate to excess $\mathrm{HCl}$ in methanol at $95{ }^{\circ} \mathrm{C}$ brought about the desired intramolecular Mannich reaction to generate azatricyclo[4.4.0.0 $\left.0^{2,8}\right]$ decanone 61. This product, whose structure was secured readily by NMR and mass spectrometric analysis, was isolated in $44 \%$ yield.

With the successful sequential base-promoted oxy-aza-Cope-Mannich sequence developed we turned to examine the related process with intermediates that contained functionality that plausibly could be employed to fashion the terminal vinyl and hydropyran fragments of gelsemine. We began by examining a sequence in which the hydroxymethylene unit of gelsemine would be present from the outset. This study commenced with the Diels-Alder cycloaddition of siloxy diene 49 with methyl $(E)$-4-benzyloxy-2-butenoate (62) (Scheme 8). When conducted in the presence of $\mathrm{AlCl}_{3}$ at $-78^{\circ} \mathrm{C}$, this reaction delivered a 7:1 mixture of endo and exo cycloadducts in $71 \%$ yield, from which the endo epimer $\mathbf{6 3}$ was separated readily by chromatography. Allylic oxidation of adduct 63 with selenium dioxide gave aldehyde 64 , which upon standard Wittig methylenation provided diene $\mathbf{6 5}$ in $68 \%$ yield for the two steps. Saponification of the methyl ester of $\mathbf{6 5}$, Curtius rearrangement of the derived acid, and alkaline hydrolysis of the resulting isocyanate delivered primary amine 67 in $60 \%$ overall yield. The cyanomethyl group was introduced next by reaction of $\mathbf{6 7}$ with chloroacetonitrile in the presence of tetrabutylammonium iodide to deliver amino nitrile $\mathbf{6 8}$ in $65 \%$ yield. Finally the silyl protecting group was removed using TBAF giving the oxy-aza-Cope precursor 69 in $91 \%$ yield. However, exposing 69 to $\mathrm{KH}$ to initially form formaldimine alkoxide $\mathbf{7 0}$ did not effect the desired anionic aza-Cope rearrangement; when this reaction was quenched with methyl chloroformate, only the tricyclic oxazolidine $\mathbf{7 1}$ was isolated (43\% yield).

Presumably the benzyloxymethyl side chain of $\mathbf{7 0}$ is responsible for imine-alkoxide $\mathbf{7 0}$ failing to undergo [3,3]-sigmatropic rearrangement. As depicted in Scheme 1, this substituent would emerge after [3,3]-sigmatropic rearrangement on the congested concave face of the cishydroisoquinoline product. Presumably this extra steric encumbrance is sufficient to prevent the sigmatropic reorganization. We had no choice but to postpone installation of the hydroxymethyl group until after the base-promoted oxy-aza-Cope rearrangement/Mannich cyclization sequence. Bromoazatricyclodecane 18 (Figure 2) emerged as a logical target, foreseeing the exo-oriented bromine at $\mathrm{C} 16$ as a handle for eventual installation of the hydroxymethyl group.

The ultimately successful synthesis of rearrangement substrate $\mathbf{1 8}$ began with the 8:1 mixture of Diels-Alder cycloadducts 50, which was prepared on large scale in $90 \%$ overall yield from 
3-methylanisole (see Scheme 6). Allylic oxidation of $\mathbf{5 0}$ provided a mixture of epimeric enals. These products could be separated on large scale by flash chromatography to provide the required endo epimer $\mathbf{7 2}$ in $80 \%$ yield (Scheme 9). Wittig methylenation of aldehyde $\mathbf{7 2}$, followed by saponification of the diene product delivered acid $\mathbf{7 4}$ in $86 \%$ yield for the two steps. Curtius rearrangement of acid $\mathbf{7 4}$ was effected using triphenylphosphoryl azide in refluxing toluene, and the resulting isocyanate was trapped at room temperature with 4methoxybenzyl alcohol to give the $p$-methoxybenzyl carbamate (Moz) $\mathbf{7 5}$ in 72\% yield. Exposure of $\mathbf{7 5}$ to trifluoroacetic acid at room temperature in the presence of anisole cleaved the carbamate to provide the corresponding primary amine in high yield. ${ }^{54}$ Reaction of this crude primary amine with formalin and $\mathrm{KCN}$ in a $\mathrm{pH} 7$ buffer solution then delivered cyanomethylamine $\mathbf{7 6}$ in $81 \%$ yield for the two steps. Finally, liberation of the hydroxyl group of 76 using TBAF provided the crystalline aza-Cope rearrangement precursor $\mathbf{7 7}$ in $90 \%$ yield.

Azatricyclo[4.4.0.0 $0^{2,8}$ ]decanone $\mathbf{1 8}$ was assembled from bicyclooctenylamine $\mathbf{7 7}$ in three additional steps. The sequence was initiated by base-promoted aza-Cope rearrangement brought about by exposing 77 to excess potassium hydride and 18 -crown-6 at room temperature in THF. Quenching the resulting rearrangement product with methyl chloroformate provided a mixture of regioisomeric carbamate enecarbonates 78. Selective cleavage of the carbonate functionality of this crude product with methanolic $\mathrm{KOH}$ at room temperature gave cishydroisoquinoline enecarbamate $\mathbf{7 9}$ in $81 \%$ overall yield from cyanomethylamine $\mathbf{7 7}$. Incorporation of the bromine substituent was realized without complications by reaction of enecarbamate 79 with 1.1 equiv of bromine and excess 1,2,2,6,6-pentamethylpiperidine (PMP) to generate $\beta$-bromo enecarbamate $\mathbf{8 0}$. This product was not purified, but directly heated at reflux in trifluoroacetic acid to provide azatricyclo[4.4.0.0 $0^{2,8}$ ]decanone $\mathbf{1 8}$ as a single stereoisomer in $67 \%$ overall yield from enecarbamate 79. $58{ }^{1} \mathrm{H}$ NMR NOE studies suggested that the bromine substituent was oriented on the exo face of the azatricyclic ring system, a conclusion that was confirmed by single crystal X-ray analysis of ethylene ketal derivative 82. After extensive optimization, the sequence summarized in Scheme 9 allowed gram quantities of azatricyclo[4.4.0.0 $0^{2,8}$ decanone $\mathbf{1 8}$ to be prepared from commercially available 3 -methylanisole in an overall yield of $16 \%$ for the 12 steps.

The configuration of the bromine substituent in azatricyclic product $\mathbf{1 8}$ deserves comment. We assume that $\beta$-bromo enecarbamate $\mathbf{8 0}$ kinetically protonates from the convex face to deliver initially $N$-acyloxyiminium-ion epimer $\mathbf{8 3}$ (Scheme 10). However, Mannich cyclization of this epimer is not observed because the boat conformation of the azacyclic ring that would be required to achieve proper overlap in the cyclization step thrusts the bulky bromine substituent directly under the carbocyclic ring. Thus, $\mathbf{8 3}$ equilibrates by way of $\mathbf{8 0}$ with epimer $\mathbf{8 4}$, the latter undergoing Mannich cyclization as depicted in transition structure $\mathbf{8 1}$ to deliver azatricyclodecanone $\mathbf{1 8 .}$

\section{Conclusion}

Iminium ions and $N$-acyloxyiminium ions derived from endo-oriented 1-methoxy- or 1hydroxybicyclo[2.2.2] oct-5-enylamines do not undergo cationic aza-Cope rearrangement to form cis-hydroisoquinolinium ions (e.g., $\mathbf{1 9} \rightarrow \mathbf{2 1}$, Scheme 1), a failure that we ascribe to two factors: bond formation being advanced with respect to bond cleavage in this sigmatropic rearrangement, and the tricyclo[4.4.0.0 $\left.0^{0,0}\right]$ decane-like pericyclic transition state being of high energy. ${ }^{32,34}$ However, the analogous base-promoted oxy-aza-Cope rearrangement does take place, which we associate with bond cleavage being advanced over bond formation in this anionic sigmatropic rearrangement. ${ }^{50}$ Moreover we demonstrated for the first time that the azatricyclo[4.4.0. $\left.0^{2,8}\right]$ decane core fragment and the C5-C6 bond of gelsemine can be formed by Mannich cyclization of a cis-hydroisoquinolone precursor. ${ }^{59}$ Using a sequential basepromoted oxy-aza-Cope rearrangement-Mannich cyclization sequence, 26,40 gram quantities 
of azatricyclo[4.4.0.0 $\left.0^{2,8}\right]$ decanone $\mathbf{1 8}$, a central intermediate in our total synthesis of $( \pm)$ gelsemine, ${ }^{40}$ was prepared from 3 -methylanisole in 12 steps and $16 \%$ overall yield.

\section{Supplementary Material}

Refer to Web version on PubMed Central for supplementary material.

\section{Acknowledgment}

This work was supported by the National Institute of Health (HL-25854). C.J.O. gratefully acknowledges the American Cancer Society for postdoctoral fellowship support (PF-98-002-01). We also thank Dr. John Greaves and Mr. John Mudd of the UCI mass spectroscopy facility, Dr. Joseph Ziller of the UCI X-ray crystallography laboratory and Dr. Jiejun Wu of the UCI NMR spectroscopy facility for their technical support.

\section{References}

2. For reviews of the literature concerning Gelsemium alkaloids, see: (a)SaxtonJEManskeRHFThe Alkaloids1965Vol. 8NYAcademic Press93117(b)BindraJSManskeRHFThe Alkaloids1973Vol. 14NYAcademic Press83121(c)LiuZ-JLuR-RBrossiAThe Alkaloids1988Vol.33San DiegoAcademic Press83140 (d) Saxton JE. Nat. Prod. Rep 1992;9:393-446.(e)TakayamaHSakaiS-JCordellGAThe Alkaloids1997Vol. 49NYAcademic Press178

3. Wormley TG. Am. J. Pharm 1870;42:1-16.

4. Sonnenschein FL. Ber 1876;9:1182-1186.

5. Moore CW. J. Chem. Soc 1910;97:2223-2233.

6. Lovell FM, Pepinsky R, Wilson AJC. Tetrahedron Lett 1959;1(4):1-5.

7. Conroy H, Chakrabarti JK. Tetrahedron Lett 1959;1(4):6-13.

8. The ${ }^{1} \mathrm{H}$ - and ${ }^{13} \mathrm{C}$-NMR spectra of gelsemine have been reinvestigated; as a result, some of the original assignments have been revised, see: (a) Schun Y, Cordell GA. J. Nat. Prod 1985;48:969-971. [PubMed: 4093780] (b) Wenkert E, Chang C-J, Clouse AO, Cochran DW. J. Chem. Soc., Chem. Commun 1970:961-962.

9. Yokoshima S, Tokuyama H, Fukuyama T. Angew. Chem., Int. Ed 2000;39:4073-4075.

10. (a) Schwarz H, Marion L. J. Am. Chem. Soc 1953;75:4372-4372. (b) Wenkert E, Chang C-J, Cochran DW, Pellicciari R. Experientia 1972;28:377-379. [PubMed: 5064429]

11. Nikiforov A, Latzel J, Varmuza K, Wichtl M. Monatsh. Chem 1974;105:1292-1298.

12. (a) Schwarz H, Marion L. Can. J. Chem 1953;31:958-975. (b) Przybylska M, Marion L. Can. J. Chem 1961;39:2124-2127.

13. Wenkert E, Orr JC, Garratt S, Hansen JH, Wickberg B, Leicht CL. J. Org. Chem 1962;27:4123-4126.

14. Wichtl M, Nikiforov A, Sponer S, Jentzsch K. Monatsh. Chem 1973;104:87-98.

15. Schun Y, Cordell GA. J. Nat. Prod 1985;48:788-791. [PubMed: 3841147]

16. (a) Chou TQ, Pak C, Hou HC, Liu JC. Chin. J. Physiol 1961;5:345-352. (b) Liu C-T, Wang Q-W, Wang C-H. J. Am. Chem. Soc 1981;103:4634-4635.

17. (a) Schun Y, Cordell GA, Garland M. J. Nat. Prod 1986;49:483-487. (b) Ponglux D, Wongseripipatana S, Subhadhirasakul S, Takayama H, Yokota M, Ogata K, Phisalaphong C, Aimi N, Sakai S-I. Tetrahedron 1988;44:5075-5094. (c) Lin L-Z, Schun Y, Cordell GA, Ni C-Z, Clardy J. Phytochemistry 1991;30:679-683.

18. Schun Y, Cordell GA. J. Nat. Prod 1986;49:806-808. [PubMed: 3819733]

19. For a review of synthetic work in this area, see: Lin H, Danishefsky SJ. Angew. Chem., Int. Ed 2003;42:36-51.

20. For model studies and syntheses of fragments of gelsemine, see: (a) Autrey RL, Tahk FC. Tetrahedron 1967;23:901-917. (b) Autrey RL, Tahk FC. Tetrahedron 1968;24:3337-3345. (c) Johnson RS, Lovett TO, Stevens TS. J. Chem. Soc. C-Organic 1970;6:796-800. (d) Fleming I, Michael JP. J. Chem. Soc., Perkin Trans. 1 1981:1549-1556. (e) Fleming I, Loreto MA, Michael JP, Wallace IHM. Tetrahedron Lett 1982;23:2053-2056. (f) Fleming I, Loreto MA, Wallace IHM, Michael JP. J. Chem. Soc., Perkin Trans. 1 1986:349-359. (g) Stork G, Krafft ME, Biller SA. Tetrahedron Lett 1987;28:1035-1038. 
(h) Vijn RJ, Hiemstra H, Kok JJ, Knotter M, Speckamp WN. Tetrahedron 1987;43:5019-5030. (i) Clarke C, Fleming I, Fortunak JMD, Gallagher PT, Honan MC, Mann A, Nubling CO, Raithby PR, Wolff JJ. Tetrahedron 1988;44:3931-3934. (j) Hiemstra H, Vijn RJ, Speckamp WN. J. Org. Chem 1988;53:3882-3884. (k) Choi J-K, Ha D-C, Hart DJ, Lee C-S, Ramesh S, Wu S. J. Org. Chem 1989;54:279-290. (1) Fleming I, Moses RC, Tercel M, Ziv J. J. Chem. Soc., Perkin Trans. 1 1991:617-626. (m) Hart DJ, Wu SC. Tetrahedron Lett 1991;32:4099-4102. (n) Koot W-J, Hiemstra H, Speckamp WN. J. Org. Chem 1992;57:1059-1061. (o) Hart DJ, Wu SC. Heterocycles 1993;35:135-138. (p) Takayama H, Seki N, Kitajima M, Aimi N, Sakai S-I. Nat. Prod. Lett 1993;2:271-276. (q) Johnson AP, Luke RWA, Steele RW, Boa AN. J. Chem. Soc., Perkin Trans. 1 1996:883-893. (r) Ng F, Chiu P, Danishefsky SJ. Tetrahedron Lett 1998;39:767-770. (s) Sung MJ, Lee C-W, Cha JK. Synlett 1999:561-562. (t) Avent AG, Byrne PW, Penkett CS. Org. Lett 1999;1:2073-2075. (u) Dijkink J, Cintrat J-C, Speckamp WN, Hiemstra H. Tetrahedron Lett 1999;40:5919-5922. (v) Pearson AJ, Wang X. J. Am. Chem. Soc 2003;125:13326-13327. [PubMed: 14583006] For total syntheses of (+)-gelsedine, see: (w) Beyersbergen van Henegouwen WG, Fieseler RM, Rutjes FPJT, Hiemstra H. Angew. Chem. Int. Ed 1999;38:2214-2217. (x) Beyersbergen van Henegouwen WG, Fieseler RM, Rutjes FPJT, Hiemstra H. J. Org. Chem 2000;65:8317-8325. [PubMed: 11101391] For total syntheses of (+)-koumine, see: (y) Magnus P, Mugrage B, DeLuca M, Cain GA. J. Am. Chem. Soc 1989;111:786-789. (z) Magnus P, Mugrage B, DeLuca MR, Cain GA. J. Am. Chem. Soc 1990;112:5220-5230. For formal total syntheses of (-)-koumine, see: (aa) Bailey PD, McLay NR. Tetrahedron Lett 1991;32:3895-3898. (bb) Bailey PD, McLay NR. J. Chem. Soc., Perkin Trans. I 1993:441-449.

21. For early studies from our laboratories, see: (a) Abelman MM, Oh T, Overman LE. J. Org. Chem 1987;52:4130-4133. (b) Earley WG, Jacobsen EJ, Meier GP, Oh T, Overman LE. Tetrahedron Lett 1988;29:3781-3784. (c) Earley WG, Oh T, Overman LE. Tetrahedron Lett 1988;29:3785-3788. (d) Madin A, Overman LE. Tetrahedron Lett 1992;33:4859-4862. (e) Overman LE, Sharp MJ. J. Org. Chem 1992;57:1035-1038.

22. (a) Sheikh Z, Steel R, Tasker AS, Johnson AP. J. Chem. Soc., Chem. Commun 1994:763-764. (b) Dutton JK, Steel RW, Tasker AS, Popsavin V, Johnson AP. J. Chem. Soc., Chem. Commun 1994:765-766.

23. (a) Newcombe NJ, Ya F, Vijn RJ, Hiemstra H, Speckamp WN. J. Chem. Soc., Chem. Commun 1994:767-768. (b) Speckamp WN, Newcombe NJ, Hiemstra H, Ya F, Vijn RJ, Koot W-J. Pure \& Appl. Chem 1994;66:2163-2166.

24. (a) Kuzmich D, Wu SC, Ha D-C, Lee C-S, Ramesh S, Atarashi S, Choi J-K, Hart DJ. J. Am. Chem. Soc 1994;116:6943-6944. (b) Atarashi S, Choi J-K, Ha D-C, Hart DJ, Kuzmich D, Lee C-S, Ramesh S, Wu SC. J. Am. Chem. Soc 1997;119:6226-6241.

25. (a) Fukuyama T, Liu G. J. Am. Chem. Soc 1996;118:7426-7427. (b) Fukuyama T, Liu G. Pure \& Appl. Chem 1997;69:501-505.

26. Madin A, O’Donnell CJ, Oh T, Old DW, Overman LE, Sharp MJ. Angew. Chem., Int. Ed 1999;38:2934-2936.

27. (a) Ng FW, Lin H, Tan Q, Danishefsky SJ. Tetrahedron Lett 2002;43:545-548. (b) Hong L, Ng FW, Danishefsky SJ. Tetrahedron Lett 2002;43:549-551. (c) Ng FW, Lin H, Danishefsky SJ. J. Am. Chem. Soc 2002;124:9812-9824. [PubMed: 12175241]

28. For recent reviews of enantioselective generation of quaternary stereocenters, see: (a) Douglas CJ, Overman LE. Proc. Natl. Acad. Sci. U.S.A 2004;101:5363-5367. [PubMed: 14724294] (b) Denissova I, Barriault L. Tetrahedron 2003;59:10105-10146. (c) Christoffers J, Baro A. Angew. Chem., Int. Ed 2003;42:1688-1690. (d) Christoffers J, Mann A. Angew. Chem., Int. Ed 2001;40:4591-4597. (e) Corey EJ, Guzman-Perez A. Angew. Chem., Int. Ed 1998;37:388-401.

29. For a comprehensive review of the intramolecular Heck reaction, see: (a) Link JT. Org. React 2002;60:157-534. For recent reviews of the utility of intramolecular Heck reactions in complex molecule construction, see: (b) Link JT, Overman LE. Chemtech 1998;28:19-26.(c) OvermanLELinkJTDiederichFStangPJCross Coupling Reactions1998WeinheimVCH231269 (d) Dounay AB, Overman LE. Chem. Rev 2003;103(3):2945-2964. [PubMed: 12914487]

30. Overman LE, Kakimoto M. J. Am. Chem. Soc 1979;101:1310-1312.

31. Some aspects of the aza-Cope-Mannich reaction have been reviewed, see: (a) OvermanLERiccaDJTrostBMFlemingIComprehensive Organic Synthesis1991Vol. 
2OxfordPergamon Press10071046 (b) Overman LE. Acc. Chem. Res 1992;25:352-359. (c) Arend M, Westermann B, Risch N. Angew. Chem., Int. Ed 1998;37:1044-1070. (d) Overman LE. Aldrichem. Acta 1995;28:107-120. (e) Royer J, Bonin M, Micouin L. Chem. Rev 2004;104:23112352. [PubMed: 15137793]

32. Approximately $15 \mathrm{kcal} / \mathrm{mol}$ higher than that of acyclic 1,5-dienes, see: (a) Wilcott MR, Cargill RL, Sears BA. Prog. Phys. Org. Chem 1972;9:25-98. (b) Burnier JS, Jorgensen WL. J. Org. Chem 1984;49:3001-3020.

33. (a) Berson JA, Walsh EJ Jr. J. Am. Chem. Soc 1968;90:4729-4730. (b) Johnson AP, Rahman M. Tetrahedron Lett 1974;15:359-362.

34. Engler EM, Farcasiu M, Sevin A, Cense JM, Schleyer PVR. J. Am. Chem. Soc 1973;95:5769-5771.

35. Stevens RV, Lee AWM. J. Am. Chem. Soc 1979;101:7032-7035.

36. For selected examples, see: (a) McMurry JE, Isser SJ. J. Am. Chem. Soc 1972;94:7132-7137. (b) Eck CR, Hodgson GL, MacSweeney DF, Mills RW, Money T. J. Chem. Soc., Perkin Trans. I 1974:1938-1943. (c) Piers E, Geraghty MB, Smillie RD, Soucy M. Can. J. Chem 1975;53:28492864. (d) Bakuzis P, Campos OOS, Bakuzis MLF. J. Org. Chem 1976;41:3261-3264. (e) Yanagiya M, Kaneko K, Kaji T, Matsumoto T. Tetrahedron Lett 1979;20:1761-1764. (f) Collins PA, Wege D. Aust. J. Chem 1979;32:1819-1826. (g) Welch SC, Gruber JM, Chou C-Y, Willcott MR, Inners R. J. Org. Chem 1981;46:4816-4817. (h) Oppolzer W, Strauss HF, Simmons DP. Tetrahedron Lett 1982;23:4673-4676. (i) Oppolzer W, Begley T, Ashcroft A. Tetrahedron Lett 1984;25:825-828.

37. McMurry JE. J. Am. Chem. Soc 1968;90:6821-6825.

38. Woodward RB, Brutschy FJ, Baer H. J. Am. Chem. Soc 1948;70:4216-4221. [PubMed: 18105974]

39 . Portions of this work have appeared in preliminary communications. ${ }^{21 \mathrm{~b}, \mathrm{c}}$

40. See the following paper in this issue.

41. (a) Monti SA, Chen S-C, Yang Y-L, Yuan S-S, Bourgeois OP. J. Org. Chem 1978;43:4062-4069. (b) Birch AJ, Shoukry EMA, Stansfield F. J. Chem. Soc 1961:5376-5380.

42. Jessup, PJ.; Petty, CB.; Roos, J.; Overman, LE. Organic Syntheses. Collect. Vol. VI. New York: Wiley; 1988. p. 95-101.

43. Brown HC, Yoon NM. J. Am. Chem. Soc 1966;88:1464-1472.

44. (a) Alfaro I, Ashton W, McManus LD, Newstead RC, Rabone KL, Rogers NAJ, Kernick W. Tetrahedron 1970;26:201-218. (b) The endo and exo isomers are misassigned in this paper, see JacobsenEJPh.D. Dissertation1983IrvineUniversity of California

45. Overman LE, Jacobsen EJ. Tetrahedron Lett 1982;23:2741-2744.

46. Presumably from Eschweiler-Clarke reduction by contaminating amounts of formic acid.

47. Hiemstra, H.; Speckamp, WN. Comprehensive Organic Synthesis. Trost, BM.; Fleming, I., editors. Vol. 2. Oxford: Pergamon Press; 1991. p. 1047-1082.

48. For an example of generating an $N$-acyloxyiminium ion in this fashion, see: Kano S, Yokomatsu T, Yuasa Y, Shibuya S. Tetrahedron Lett 1983;24:1813-1814.

49. Attempted cationic aza-Cope rearrangement of substrates in which the methoxy group was replaced by a free hydroxy group led only to formation of the corresponding oxazolidine.

50. Steigerwald ML, Goddard WA III, Evans DA. J. Am. Chem. Soc 1979;101:1994-1997.

51. Evans DA, Golob AM. J. Am. Chem. Soc 1975;97:4765-4766.

52. (a) Kakimoto M, Okawara M. Chem. Lett 1979:1171-1174.Okazaki, ME. Ph.D. Dissertation. Irvine: University of California; 1986.

53. Rubottom GM, Gruber JM. J. Org. Chem 1977;42:1051-1056.

54. Attempted alkaline hydrolysis of the isocyanate to directly produce the amine resulted in formation of substantial amounts of the dimeric urea.

55. Formaldehyde imines, unless substituted with extremely bulky substituents on nitrogen, cannot be isolated as they rapidly trimerize to form hexahydro-1,3,5-triazines. $56 \mathrm{a}$

56. (a) Overman LE, Burk RM. Tetrahedron Lett 1984;25:1635-1638. (b) Overman LE, Osawa T. J. Am. Chem. Soc 1985;107:1698-1701.

57. The relative configuration of the cyano substituent was established by single-crystal X-ray analysis of the $N$-benzoyl derivative. 
58. The formyl analog $(\mathbf{7 9 / 8 0}$ with $\mathrm{R}=\mathrm{CHO})$, which is available from the reaction of $\mathbf{7 9}$ with Vilsmeier reagent, does not cyclize under these conditions

59. Johnson subsequently employed a Mannich cyclization of a more advanced intermediate to form this bond of gelsemine in his inaugural total synthesis of $( \pm)$-gelsemine. ${ }^{22}$ 


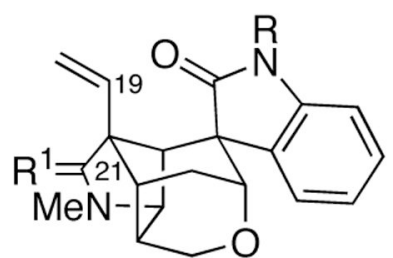

$\mathrm{R}=\mathrm{H}, \mathrm{R}^{1}=\mathrm{H}, \mathrm{H} \quad$ gelsemine (1)

$\mathrm{R}=\mathrm{OMe}, \mathrm{R}^{1}=\mathrm{H}, \mathrm{H}$ gelsevirine (2)

$\mathrm{R}=\mathrm{H}, \mathrm{R}^{1}=\mathrm{O} \quad$ 21-oxogelsemine (3)

$\mathrm{R}=\mathrm{OMe}, \mathrm{R}^{1}=\mathrm{O} \quad$ 21-oxogelsevirine (4)<smiles>[Z7]c1ccc2c(c1)NC(=O)[C@]1(CC)C[C@@H]2NC1[R7]</smiles>

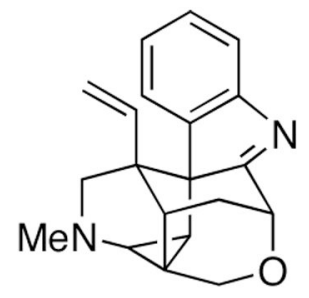

koumine (10)<smiles></smiles>

rankinidine (14)

$\mathrm{R}=\mathrm{OMe}, \mathrm{R}^{1}=\mathrm{OMe}, \mathrm{R}^{2}=\mathrm{H}$ gelsemicine (5)

$\mathrm{R}=\mathrm{OMe}, \mathrm{R}^{1}=\mathrm{R}^{2}=\mathrm{H} \quad$ gelsedine (6)

$\mathrm{R}=\mathrm{R}^{1}=\mathrm{OMe}, \mathrm{R}^{2}=\mathrm{OH} \quad$ hydroxygelsemicine (7)

$\mathrm{R}=\mathrm{OMe}, \mathrm{R}^{1}=\mathrm{H}, \mathrm{R}^{2}=\mathrm{OH} \quad 14 \beta$-hydroxygelsedine (8)

$\mathrm{R}=\mathrm{R}^{1}=\mathrm{R}^{2}=\mathrm{H} \quad$ gelsenicine (9)<smiles>[R7]C(C)C12CN(C)C3CC(COC31)C21C(=O)Nc2ccccc21</smiles>

$\mathrm{R}=\mathrm{OMe}, \mathrm{R}^{1}=\mathrm{OH} \quad 19-(R)$-hydroxydihydrogelsevirine (11)

$\mathrm{R}=\mathrm{OMe}, \mathrm{R}^{1}=\mathrm{OAc} 19-(R)$-acetoxydihydrogelsevirine (12)

$\mathrm{R}=\mathrm{H}, \mathrm{R}^{1}=\mathrm{OH} \quad 19-(R)$-hydroxydihydrogelsemine (13)

Figure 1.

Gelsemium alkaloids. 


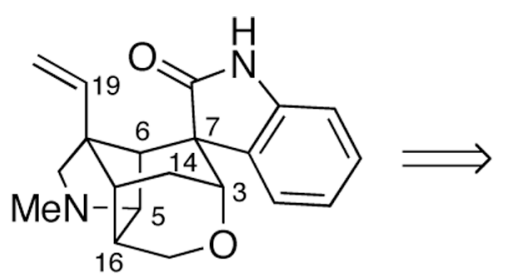

1
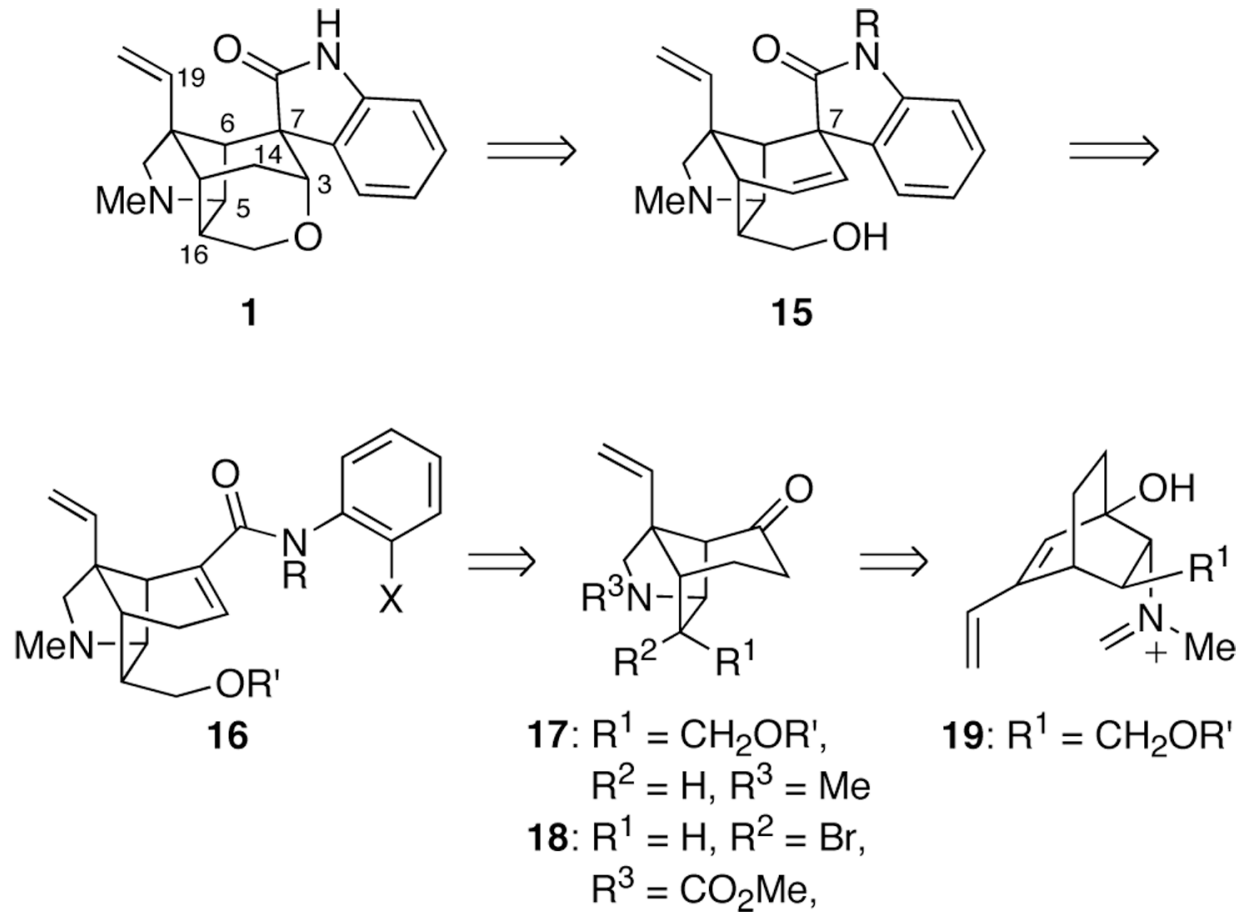

15

Figure 2.

Initial retrosynthetic analysis. 


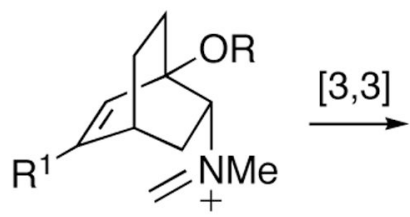

43

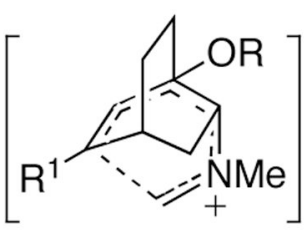

44<smiles>[R7]C12C=C(O)CC[C@H]1CC=[N+](C)C2</smiles>

45

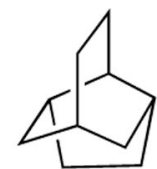

tricyclo[4.3.1.0 $\left.0^{3,7}\right]$ decane (46) steric energy $=30.4 \mathrm{kcal} / \mathrm{mol}$ (MM2)

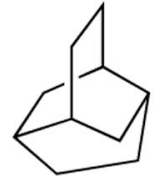

$$
\begin{gathered}
\text { tricyclo[4.4.0.0 } 0,0] \text { decane }(47) \\
\text { steric energy }=32.6 \mathrm{kcal} / \mathrm{mol} \\
(\mathrm{MM} 2)
\end{gathered}
$$

Figure 3.

Transition structure of the cationic aza-Cope rearrangement of $\mathbf{4 3}$ and the steric energies of related tricyclodecanes. 


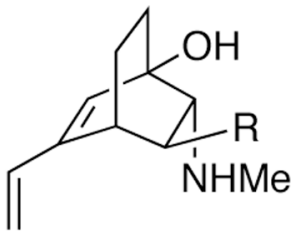

20: $\mathrm{R}=\mathrm{CH}_{2} \mathrm{OR}^{\prime}$

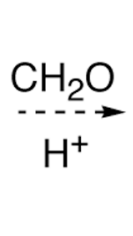

$\mathrm{H}^{+}$

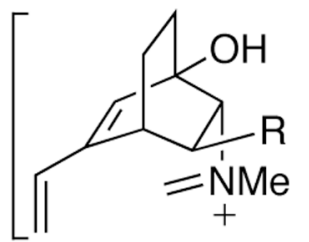

19: $\mathrm{R}=\mathrm{CH}_{2} \mathrm{OR}^{\prime}$<smiles>C#CC[C@H]1C=[N+](C)CC[C@]12C=C(O)CC[C@H]2C=O</smiles>

21

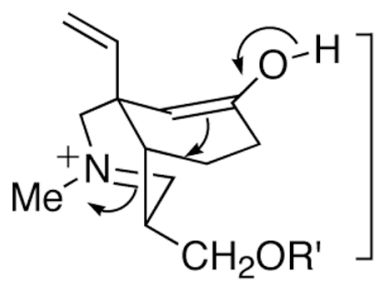

22

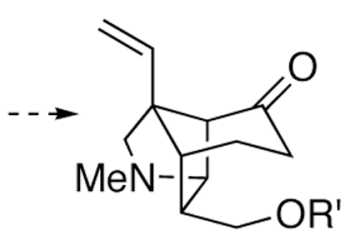

17

Scheme 1. 
<smiles>CC1=C2[C@@H]3OC(=O)[C@@H](C)[C@H]3CCC2(C)C=CC1=O</smiles><smiles>[X]OC(=O)[C@H](C)[C@H]1CC[C@@]2(C)C=CC(=O)C(C)C2C1=O</smiles>
$\alpha$-santonin (23)

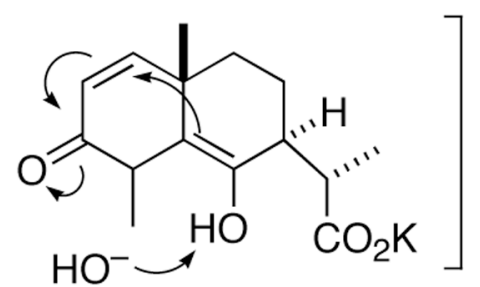

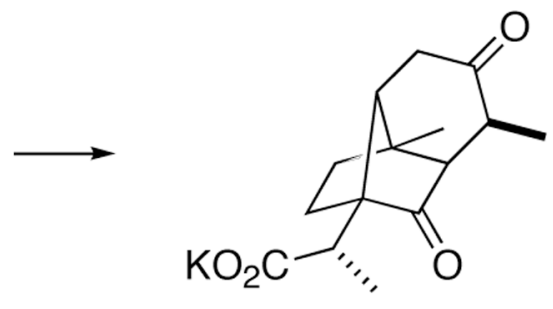

potassium santanoate

Scheme 2. 
<smiles>C=CC(=O)OC</smiles><smiles>[R7]C1([R7])CC2CCC1C=C2C</smiles><smiles>CO[C@H](O)O[Na]</smiles>

24

25: $\mathrm{R}^{1}=\mathrm{H}, \mathrm{R}^{2}=\mathrm{CO}_{2} \mathrm{Me}$

27

26: $\mathrm{R}^{1}=\mathrm{CO}_{2} \mathrm{Me}, \mathrm{R}^{2}=\mathrm{H}$

1. $\operatorname{EtOC}(\mathrm{O}) \mathrm{Cl}$

2. $\mathrm{NaN}_{3}$

3. $\mathrm{EtOH}$

$54 \%$

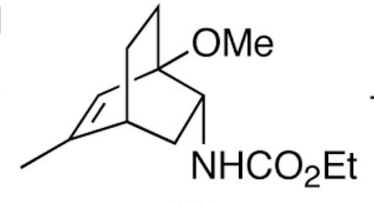

28

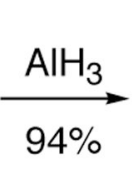

$94 \%$

5

29<smiles>C=NC1C2CCC(OC)(C(C)C2)C1C</smiles>

30

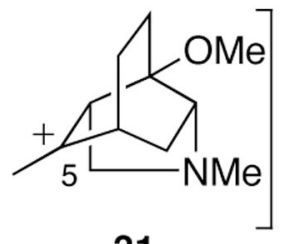

31 $\underset{76 \%}{\stackrel{-\mathrm{H}^{+}}{\longrightarrow}}$<smiles>COC12CCC(CC1)C(C)C2C</smiles>

32

Scheme 3. 


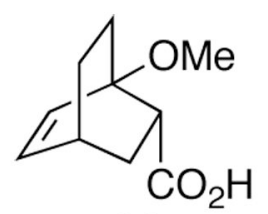

33
1. $\mathrm{EtOC}(\mathrm{O}) \mathrm{Cl}$

2. $\mathrm{NaN}_{3}$

3. $\mathrm{EtOH}$ $57 \%$ $\left(\mathrm{CH}_{2} \mathrm{O}\right)_{n}$ $\mathrm{HCO}_{2} \mathrm{H}$, rt $90 \%$

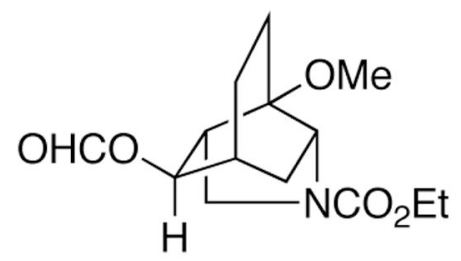

37

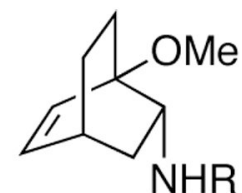

$\left.\begin{array}{l}\text { 34: } \mathrm{R}=\mathrm{CO}_{2} \mathrm{Et} \\ \text { 35: } \mathrm{R}=\mathrm{Me}\end{array}\right] \mathrm{AlH}_{3}, 87 \%$

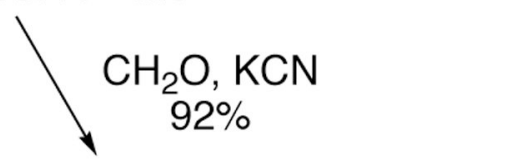

Scheme 4.

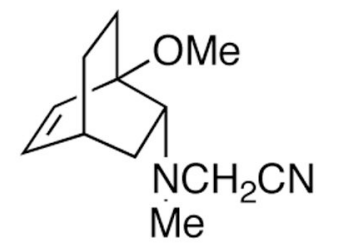

36 

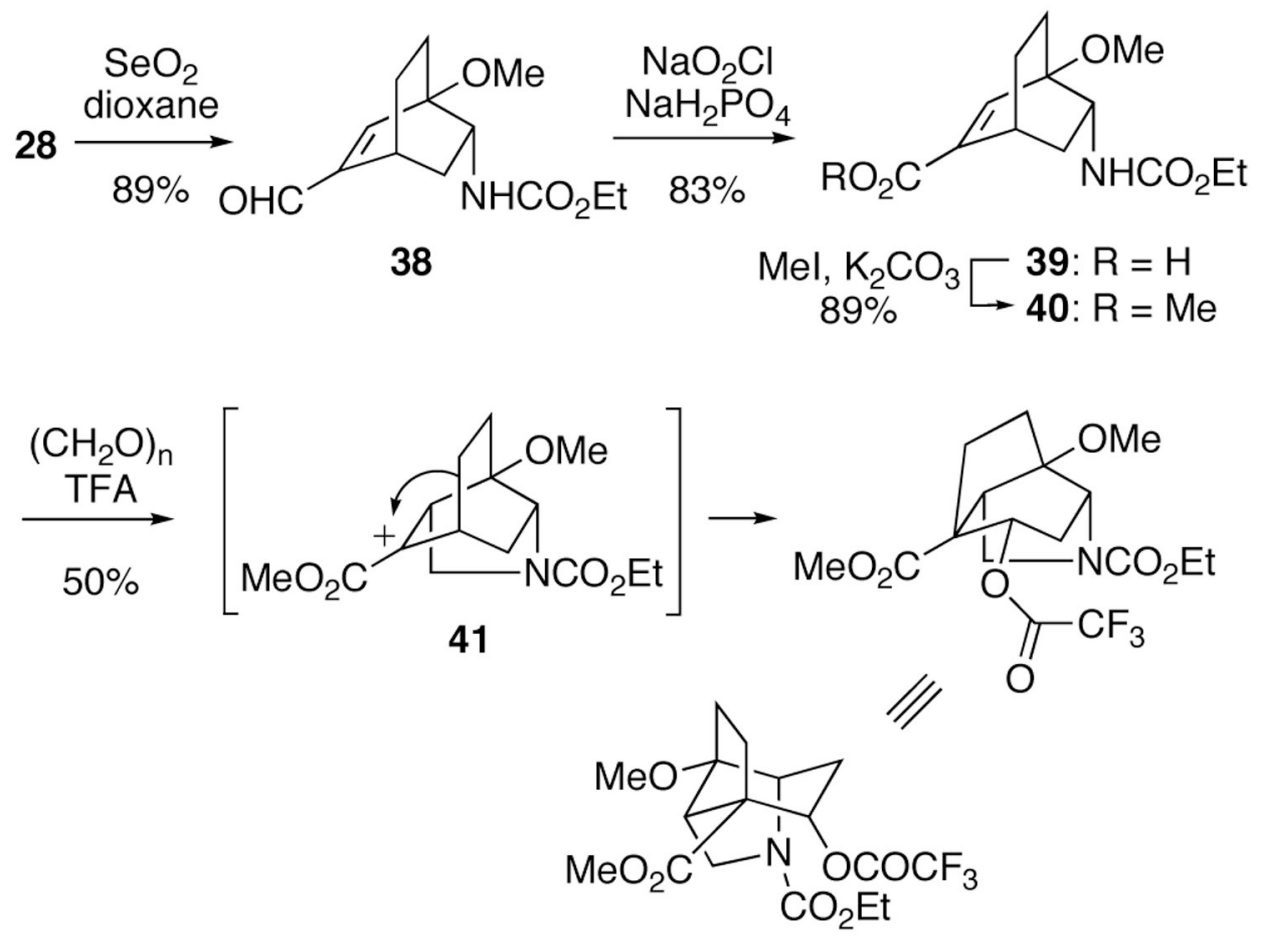

42 (X-ray)

Scheme 5. 


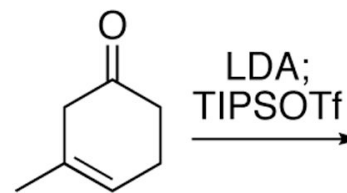

48<smiles>CC1=CCCC(OC(C)C)=C1</smiles>

49 (92\% from 3-methylanisole)

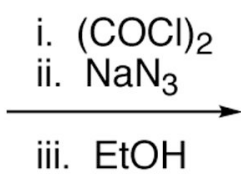
$68 \%$
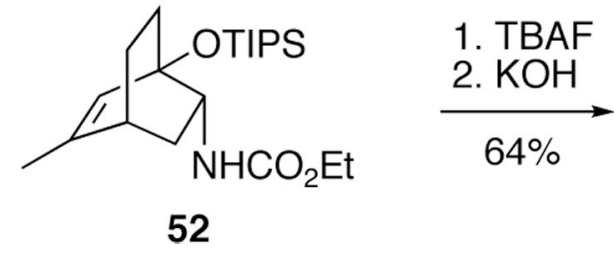

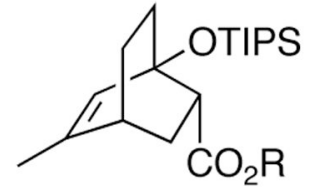

(8:1 endo/exo)

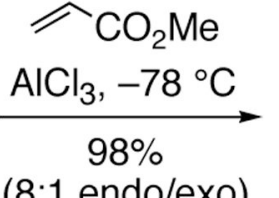

$\mathrm{KOH}, 74 \%$ 50: $R=M e$ $51: \mathrm{R}=\mathrm{H}$

Scheme 6. 


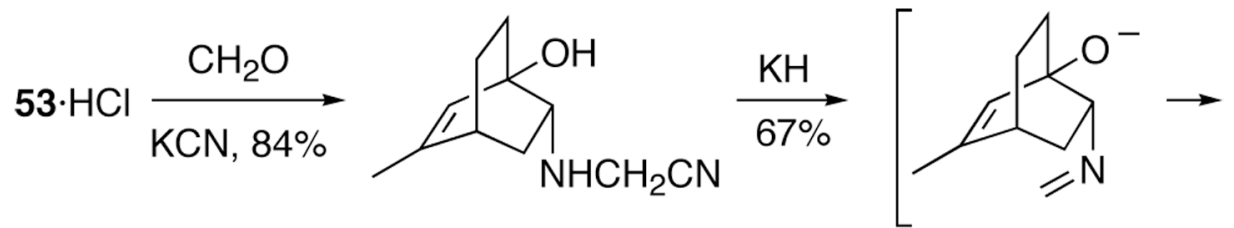

54<smiles>CC12C=C([O-])CC[C@H]1CC=NC2</smiles>

56

$\downarrow \mathrm{H}_{2} \mathrm{O}$<smiles>CC12CN=CCC1CCC(=O)C2</smiles>

57 $\underset{67 \%}{\stackrel{\mathrm{HCN}}{\longrightarrow}}$

$$
\mathrm{MeSO}_{3} \mathrm{Me}-58: \mathrm{R}=\mathrm{H}
$$<smiles>CC12CNC(C#N)CC1CCC(=O)C2</smiles>

59: $R=M e$ $\downarrow \mathrm{HCl}, \mathrm{MeOH}$

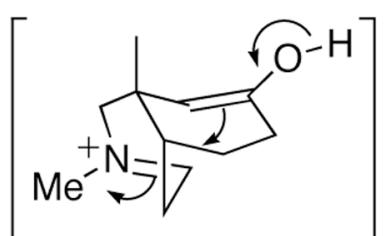

60

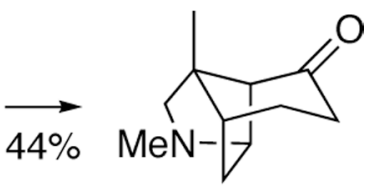

61

Scheme 7. 


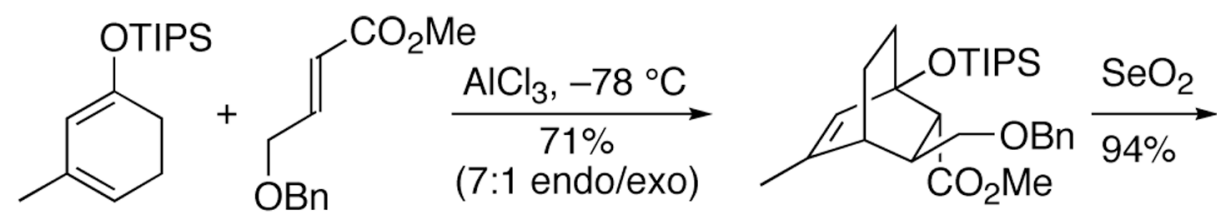

49

62
63

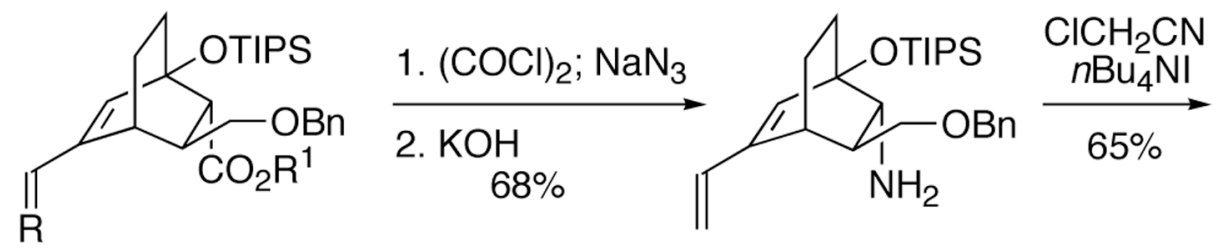

64: $R=O, R^{1}=M e$

65: $\mathrm{R}=\mathrm{CH}_{2}, \mathrm{R}^{1}=\mathrm{Me} \leftarrow \mathrm{Ph}_{3} \mathrm{P}=\mathrm{CH}_{2} 72 \%$

66: $\mathrm{R}=\mathrm{CH}_{2}, \mathrm{R}^{1}=\mathrm{H} \quad \mathrm{KOH} 88 \%$

67

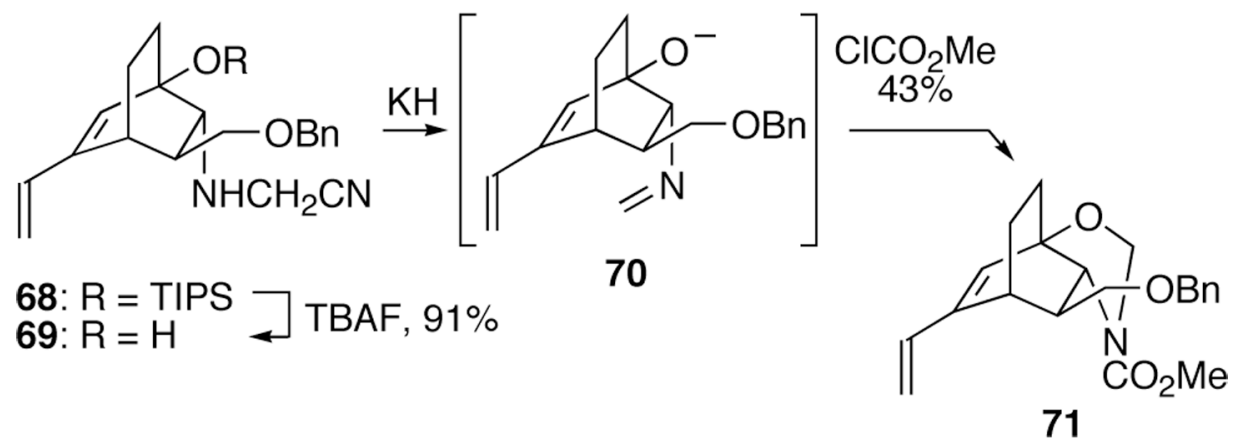

Scheme 8 . 


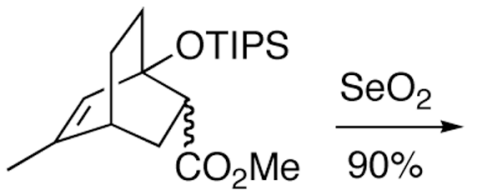

50

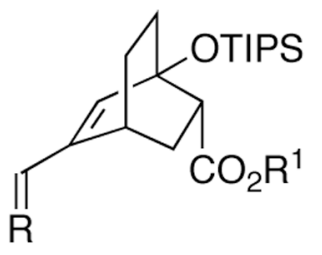

$(\mathrm{PhO})_{2} \mathrm{P}(\mathrm{O}) \mathrm{N}_{3}$, $\mathrm{Et}_{3} \mathrm{~N} ; \mathrm{PMB}-\mathrm{OH}$ $72 \%$

$$
\begin{aligned}
& \mathrm{Ph}_{3} \mathrm{P}=\mathrm{CH}_{2} 95 \%\left[\begin{array}{l}
\text { 72: } \mathrm{R}=\mathrm{O}, \mathrm{R}^{1}=\mathrm{Me} \\
\mathrm{KOH} \mathrm{91 \%}
\end{array} \longrightarrow 73: \mathrm{R}=\mathrm{CH}_{2}, \mathrm{R}^{1}=\mathrm{Me}\right. \\
& \longrightarrow 74: \mathrm{R}=\mathrm{CH}_{2}, \mathrm{R}^{1}=\mathrm{H}
\end{aligned}
$$
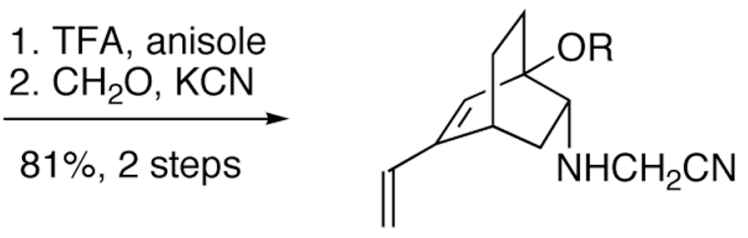

75

TBAF $90 \% \square 76: R=$ TIPS
$\rightarrow 77: R=H$

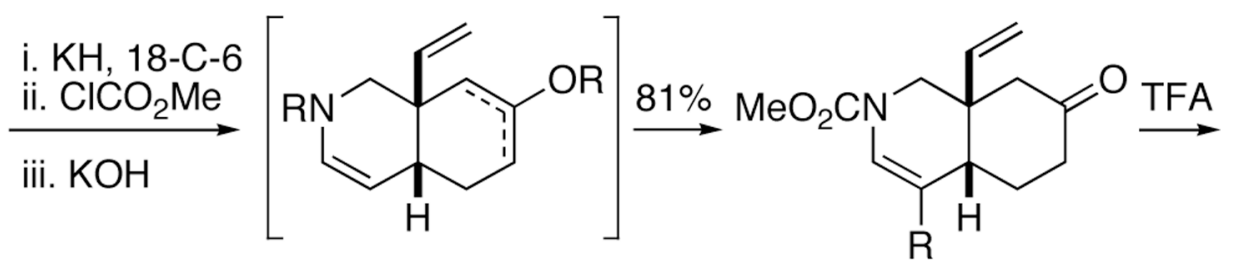

78: $\mathrm{R}=\mathrm{CO}_{2} \mathrm{Me}$

$$
\begin{aligned}
& \mathrm{Br}_{2}, \mathrm{PMP} \longrightarrow \text { 79: } \mathrm{R}=\mathrm{H} \\
& \mathbf{8 0}: \mathrm{R}=\mathrm{Br}
\end{aligned}
$$

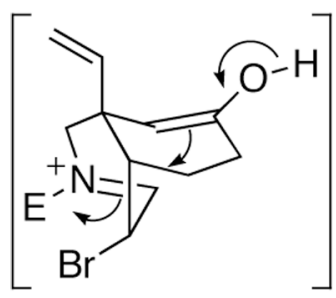

81

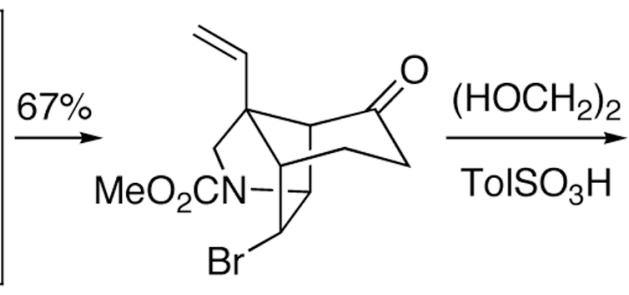

18

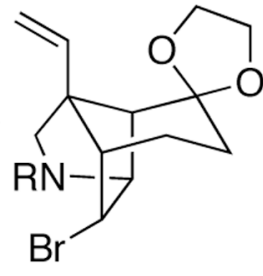

82 (X-ray)

Scheme 9. 


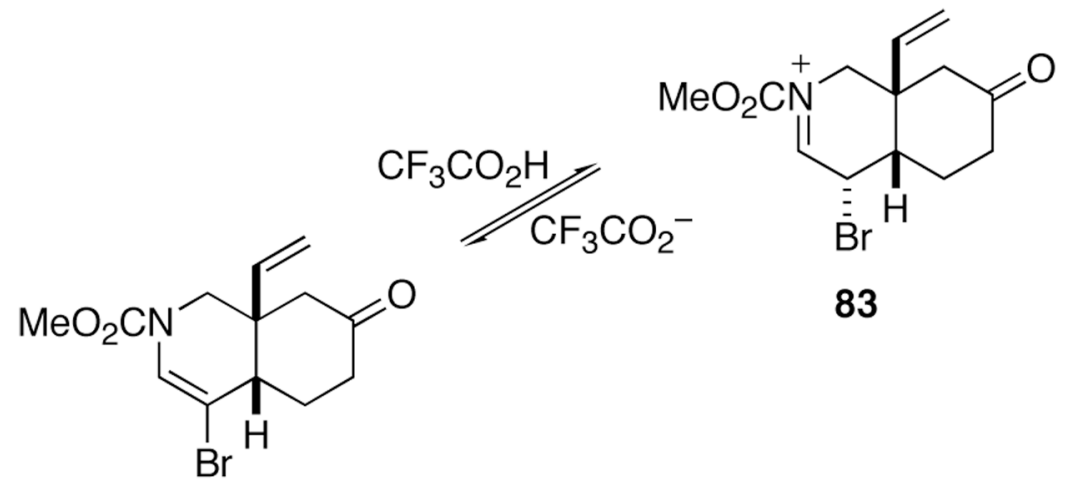

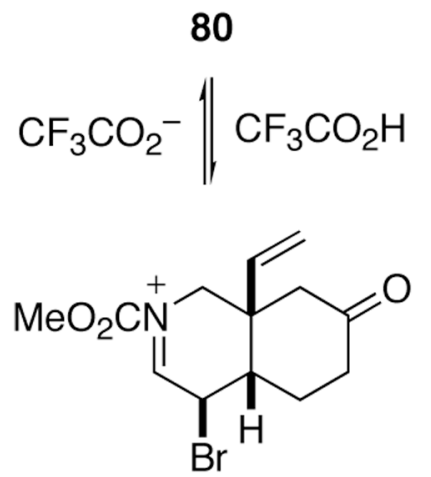

84

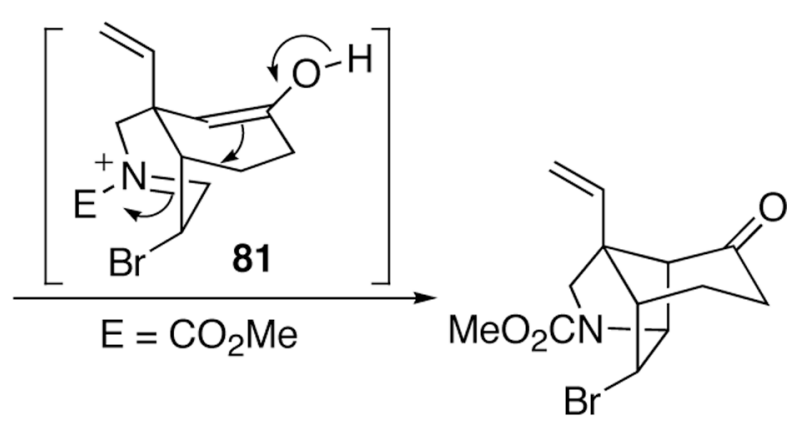

18

Scheme 10. 